\title{
PARTICULARITIES OF EVIDENCE OF THE GOODS
}

\author{
Ph.D. Student Gabi Dragu, gabi.dragu@mfinante.ro
}

\begin{abstract}
The main requirement addressed to the public book-keeping as support for the managing activity is the improvement of the quality for the financial information.

The manner for accomplishing this task is: passing from a pay-desk book-keeping focused on entries (resources) - cash accounting to a commitment book-keeping focused on outgoings (economical results) - accrual accounting.

The project will refer to the specific differences in emphasizing the confiscated goods or entered against the law in the state's property, comparing to that of a usual present activity, as a result of applying the commitment book-keeping and the new legal frame which represents the basis of this activity.
\end{abstract}

The main requirement addressed to the public book-keeping as support for the managing activity is the improvement of the quality for the financial information.

The information supplied by the annual financial situations must be:

- relevant - they can influence the economic decisions of the users;

- believable - they must totally represent the financial position and the patrimonial result of the public institution;

- neutral - they must reflect the economical reality as exactly as possible;

- cautiously - they must apply book-keeping politics which do not lead to a over-valuation of the actives and incomes or to a under-evaluation of expenses and debts;

- complete under all important aspects;

The manner for accomplishing this task is: passing from a pay-desk book-keeping focused on entries (resources) - cash accounting to a commitment book-keeping focused on outgoings (economical results) - accrual accounting.

"Cash accounting" = book-keeping basing on cash recognizes the transactions and experiments when cash is received of paid.

The result of the budgetary execution is determined at the end of the exercise as the difference between the received cash and the paid cash.

Differing from this, "Accrual accounting" = the commitment book-keeping recognizes the transactions and events when an economical value, a book debt or an obligation is created, transformed, transferred or canceled.

The patrimonial result is an economical result and is determined as the difference between the incomes for the current period, with no importance if they were cashed in or paid expenses.

The recording of the economic - financial operations is made in accounts for the five known groups: Actives, Debts, Capitals, Incomes, Expenses.

Among the advantages of the commitment book-keeping are:

- it offers the information as complete as possible comparing to the cash book-keeping;

- it focuses on transparency an accuracy;

- it provides a clearer image on the actives and passives of the public institution.

The legal frame through which is realized:

- The book-keeping law no. 82/1991, re-published in 2005 with the following modifications and completions;

- The law regarding the public finances no. 500/2002; 
- The classification of the indicators for public finances approved by Order of The Public Finances Minister no. 1954/2005;

- The Order of The Public Finances Minister no. 1917/2005 with the following modifications and completions;

The legal frame regarding the activity of capitalizing on the confiscated goods or entered in the property of the state:

- Ordnance no. 14 on $31^{\text {st }}$ January 2007 for re-establishing the manner and condition of capitalization on the goods entered, against the law, in the private property of the state;

- The Decision no.731 on $4^{\text {th }}$ July 2007 regarding the approval of the manner of applying the Ordnance no. 14/2007 for re-establishing the manner and condition of capitalization on the goods entered, against the law, in the private property of the state; presented.

As follows, particular aspects revealed by the specific of the activity of these goods will be

The entrance of the goods in order to be accepted and evaluated bases on:

- account sheet;

- the original donor paper and the acceptance, by order of The Economy and Finances Minister;

- for the goods resulting from vacant sequences, the property title on these of the state represents the sequent vacancy certificate from the public notary;

- for the payment alternatives the handing-receiving report with a copy of the entrancereceiving note elaborated by the specialized juridical persons or authorized physical persons to commercialize these goods;

\section{after it.}

The evidence of the goods has several stages until the moment of the evaluation and

As follows, for the goods accepted for evaluation in order to be capitalized on:

a) Until the moment of the evaluation: the evidence is assured by the sheet of the goods in course of evaluation which can be verified for concordance with the entrance reports for the specific period. Without evaluation, these goods can not be capitalized on using accounts. For those which are in course of clarification the right owner, the evidence is technically operative.

b) The evidence at the checking organs for the legally confiscated goods or entered in the property of the state according to the law, after the evaluation on the category of goods.

1) Evidence of taxed real estate or mobile goods:

347/A " Confiscated goods or entered, $=102$ "The Goods' funds which form
according to the law, in private property
of the state

1') Evidence of mobile goods resulting through capitalization on from dismemberment:

- in red the initial value:

\begin{tabular}{l}
\hline $347 / \mathrm{A}$ "Confiscated goods or entered, $=102$ "The Goods' funds which form \\
according to the law, in private property \\
of the state
\end{tabular}

- in black the new value:

\begin{tabular}{l}
$\begin{array}{l}\text { 347/A "Confiscated goods or entered, }=102 \text { "The Goods' funds which form } \\
\text { according to the law, in private property } \\
\text { of the state }\end{array}$ \\
\hline
\end{tabular}


* It is recommended to emphasize differently the place where they are by analytical accounts for the goods, the emphasizing manner being related to the clients and after the capitalization, they should be analyzed together.

Differing from the current emphasizing where is realized:

- for the real estate:

212 "Structures" $=404$ "Providers of fixed actives"

- for the good by the nature of the stocks:

$3 \mathrm{XX}$ depending on the situation $=401$ "Providers"

The usage for correspondence of a patrimonial account, of the discount account with the budget of the state instead of the account "Incomes to be achieved" is also found in the chapter IX "The transposition of the account balance in the verifying balance sheet on $31^{\text {st }}$ of December 2005 in the new plan of general accounts" by order of the Public Finances Minister no. 1917/2005 for approving the manner regarding the organization and leading of the public institutions' bookkeeping, the plan of accounts for the public institutions and the instructions for applying it with the following modifications and completions.

- Emphasizing the entrance for payments in lei:

557 "Available from the capitalization of the goods $=4481$ "Other debs to the budget" entered in the private property of the state"

- Emphasizing the entrance for payments in free convertible currency and un-convertible to NBR:

5124 "Accounts in currency" = = $\quad 4481$ "Other debs to the budget"

- Emphasizing the entrance for obtained value titles:

260 "Participation titles" = = $\quad 4481$ "Other debs to the budget"

Differing from the current emphasizing: for the acquisitions titles:

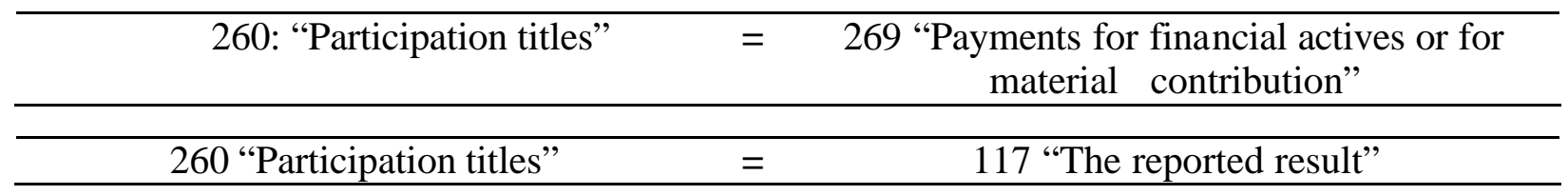

The evidence of the goods capitalization

a) Capitalization with full payment at the moment of the acquisition, through stores belonging to the capitalization organ, through selling directly from the depositing place, the place where they are, en-detail selling or by auction conditioned by full payment; report:

- Emphasizing the bills towards the clients at the mentioned value in the en-detail evaluation

\begin{tabular}{l}
4111 "Clients with less than one year term" = 4481 "Other debts to the budget" \\
Differing from: \\
\hline 4111 "Clients with less than one year term" = \\
- Emphasizing the late increases as a result for not paying in time the bills and outrunning of \\
the 5 days from the end of the auction:
\end{tabular}


4611 "Debtor with less than one year" =

4481 "Other debts to the budget"

- Emphasizing the equivalent of the goods missing at the inventory because of the staff

4282 "Other obligations related to the staff" = = 4481 "Other debts to the budget"

- Emphasizing the cashing of the sums in the account of available or cash, depending on the case, from clients, according the law:

1) in the account of available:

557 "Available from the capitalization of the = goods entered in the private property of the state

4111 "Clients with less than one year term"

2) cash at the pay-desk of the unit:

5311 "Lei pay-desk" = = $\quad 4111$ "Clients with less than one year term"

- The evidence of deposing the emphasized cash at the anterior operation:

557 "Available from the capitalization of the goods = 5311 "Lei pay-desk"

entered in the private property of the state"

- The evidence of deposing in the account of the country's budget from the account of available ( it is specific the deposing of the cashed sums in the account of available relate to the state's budget for 5 days), after the deduction of the expenses for the specific activity:

4481 "Other debts to the budget $=557$ "Available from the capitalization of the goods entered in the private property of the state"

- Emphasizing the deposing in the account of the country's budget of the cashed in sums, specific for the passing through the account of available from capitalizations followed by the deposing in the account of the state's budget:

557 "Available from the capitalization of the = 5311 "Lei pay-desk" goods entered in the private property of the state"

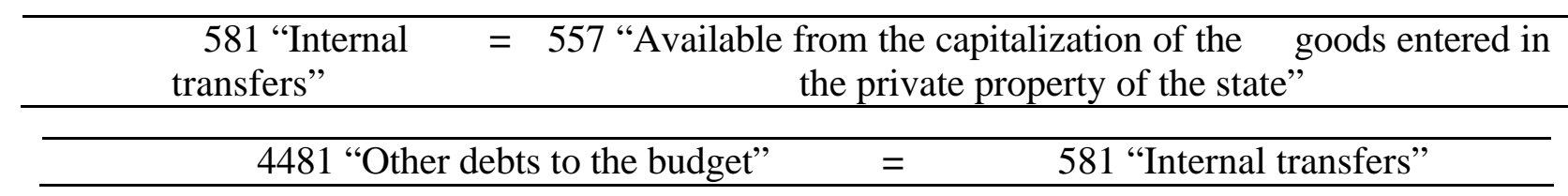

- Emphasizing the cash in of the sums in the account of available or cash, depending on the case, from the debtors in penalties, according to the law:

1) in the account of available:

557 "Available from the capitalization of the = 4611 "Debtors with less than year" goods entered in the private property of the state"

2) cash at the pay-desk of the unit:

5311 "Lei pay-desk" = $\quad 4611$ "Debtors with less than one year"

- Emphasizing the cash in sums in the account of available or cash, depending on the case, from the debtors in deficiency of financial administration, qualitative déclassé, replaced by reasons assign to the staff, according the law is similarly made using the adequate account; 
- Emphasizing the transfer of the sums from internal and external debtors to the state's budget is similarly made;

- Emphasizing the covered expenses, according to the law, from the sums obtain by capitalization, the debts are directly recorded with the debt to the state's budget:

4481 "Other debts to the budget" $=\%$

4621 "Creditors with less than one year"

401 "Providers", etc.;

Differently from the current recording:

$\%$ = 401 "Providers"

$6 \mathrm{XX}$ depending on the nature;

$3 \mathrm{XX}$, etc.

Emphasizing the payment of the expenses, according to the law, which is made from the sums obtained by capitalization:

1) through bank transfer:

\begin{tabular}{ccc}
4621 "Creditors with less than one year" $=$ & $\begin{array}{r}557 \text { "Available from the capitalization of the } \\
\text { goods entered in the private property of the state" }\end{array}$ \\
\hline 401 "Providers" & $\begin{array}{r}557 \text { "Available from the capitalization of the } \\
\text { goods entered in the private property of the state" }\end{array}$ \\
\hline
\end{tabular}

2) cash at the pay-desk of the unit:

581 "Internal transfers" = $\quad 557$ "Available from the capitalization of the goods entered in the private property of the state"

\begin{tabular}{ccc}
\hline 5311 "Lei pay-desk" & $=$ & 581 "Internal transfers" \\
\hline 4621 "Creditors with less than one year" & $=$ & 5311 "Lei pay-desk" \\
\hline 401 "Providers" & $=$ & 5311 "Lei pay-desk" \\
\hline
\end{tabular}

The evidence of subtraction from the financial administration of the sold goods:

102 "The Goods' funds which form the $=347$ "Goods confiscated or entered, according to private domain of the state." the law, in the private property of the state"

Differently from the classic recording using an account of class 6 "Expenses"

b) Capitalization with payment in instalments.

b1) Selling by auction:

The evidence is made at the selling value:

For this type of capitalization, it is specific the building and the emphasizing of the warranty for the offer of the auction's participants:

1) directly in the account of available

552 "Available for mandate sums $\quad=\quad 4621$ "Creditors with less than one year"

and sums in account"

2) cash at the pay-desk of the unit

5311 "Lei pay-desk" = $\quad=\quad 4621$ "Creditors with less than one year"

3) the deposing of the warranty at the treasury: 


\begin{tabular}{cll}
\hline 581 "Internal transfers" & $=$ & "5311 "Lei pay-desk" \\
\hline 552 "Available for mandate sums and sums in account" & $=$ & 581 "Internal transfers"
\end{tabular}

This time, the emphasizing of the bills by the clients is made at de value of buying.

- A specific aspect is emphasizing the renewal of the instalments with the rate of discount of the National Bank of Romania

4111 "Clients with less than one year term" = 4481 "Other debts to the budget"

- Emphasizing the cashing of the sums in the account of available or cash, depending on the case, from the clients, the debit related to the increases, and their transfer is made similarly.

- Emphasizing the restore of the full participation warranty at the auction to the participants that did no win the auction:

1) through bank transfer:

4621 "Creditors with less than one year" = 552 "Available for mandate sums and sums in
account"

2) cash at the pay-desk of the unit:

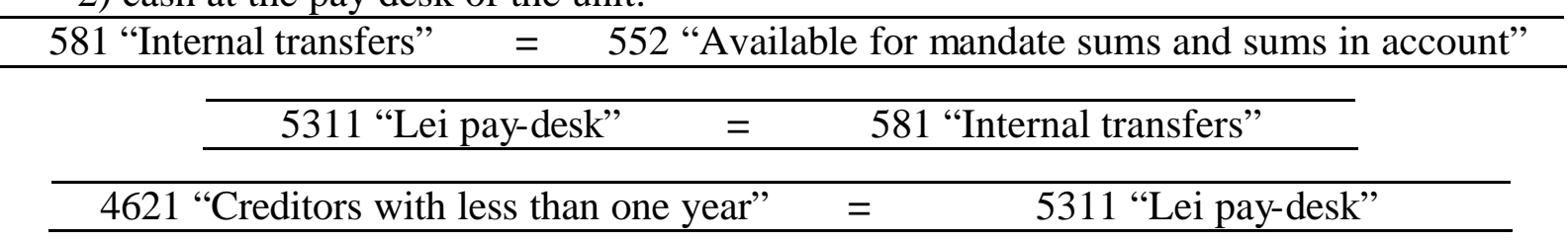

Another specific aspect is emphasizing the transfer from the account of available of the account sums of the warranty in the account of available from the capitalization of the goods which became property of the state, of the equivalent of the warranty when the auction was knocked down and the compensation of the warranty with the advance payment is chosen, in one of the cases when a legal foresight of compensation of a claim with a debt exists:

\begin{tabular}{c}
581 "Internal transfers" $=552$ "Available for mandate sums and sums in account" \\
\hline $\begin{array}{c}557 \text { "Available through capitalization of the goods } \\
\text { entered in the private property of the state" }\end{array}$
\end{tabular}

- The emphasizing of the compensation of the participation warranty with the equivalent of the goods when the auction is knocked down - in one of the cases when there is again a legal foresight of compensation of a claim with a debt:

4621 "Creditors with less than one year" = $\quad 4111$ "Clients with less than one year term"

A specific aspect of the participation condition on a auction is emphasizing the loss of the right for the winner of the auction to restore and transfer it to the budget of the state by not participating to the auction or if the winner does not pay off the sum for the goods in maximum 5 days, the transfer is made in the account of available because the sum was transferred there from the account of mandate sums in case of knocking down the auction.

\begin{tabular}{ccc}
\hline 4621 "Creditors with less than one year" $=4481$ "Other debts to the budget" \\
\hline 4481 "Other debts to the budget" = $\quad 557$ "Available from the capitalization of the goods" \\
\hline
\end{tabular}

- The evidence of the deduction from the financial administration of the sold goods, entirely paid off is similarly made to the capitalization with full payment. 
Another specific aspect is the emphasizing of the expenses which are supported by the initial purchaser:

4611 "Debtors with less than one year" =

401 "Providers";

4111 "Clients with less than one year term";

* 4621 "Creditors with less than one year";

** 4481 "Other debts to the budget", etc.

* for the difference of value for capitalization of the goods between the initial and final purchasing.

** delay increases for not paying the obligation to the state's budget, un-paid sums from the warranty etc.

- Emphasizing the compensation of the owed sum with that from the warranty until the convergence of the sum:

4621 "Creditors with less than one year" = 4611 "Debtors with less than one year"

- The evidence of the transfer of the sum in conditions when the warranty covers de owed sum, the transfer for the part of warranty exceeds the debt:

4481 "Other debts to the budget" = 557 "Available from the capitalization of the goods"

b2) The emphasizing of the direct en-gros selling with payments by instalments or in the case of the auction with only one offeror.

The emphasizing of the common aspects is made as presented previously.

c) The capitalization basing on the consignment method:

- Emphasizing the handing of the goods in consignment to a third part basing on the matching notice for the ware:

359 "Goods in custody or consignment to $=$ "Confiscated goods or entered, according to a third part" the law, in private property of the state"

- Emphasizing the deduction from the financial administration for the sold goods:

102 "Fund of the goods which represent = 359 "Goods in custody or consignment to a the private domain of the state" third part"

- Emphasizing the return of the goods which are in consignment to a third part, basing on the matching note for the ware at the checking organs:

347 "Confiscated goods or entered, according = 359 "Goods in custody or consignment to a

to the law, in private property of the state" third part"

- The emphasizing of the other common aspects is made similarly.

d) The capitalization of the sums in currency.

The emphasizing of the operations representing sums in currency:

- Emphasizing the differences of rate of exchange favorable or not and recorded as a result of the monetary availability at the current rate of exchange at NBR;

- The emphasizing of the differences of rate of exchange favorable or not recorded as a result of a judicial decision is covered from the cashed in sums.

- the difference which is not favorable:

665 "Expenses from differences of rate of exchange" $=5124$ "Accounts in currency"

- favorable difference:

5124 "Accounts in currency" $=756$ "Incomes from the differences of rate of exchange"

- Emphasizing the banking commission:

627 "Expenses with banking and assimilated services" $=5121$ "Accounts in lei" 
- Emphasizing the diminution of the debt to the budget of the state with the non-favorable rate of exchange, the banking commission:

\begin{tabular}{ll}
4481 "Other debts to the budget" & $=665$ "Expenses from differences of rate of exchange" \\
\hline 4481 "Other debts to the budget" & $=627$ "Expenses with the banking services"
\end{tabular}

- the growth of the debt to the budget of state with the favorable difference of rate of exchange:

765 "Incomes from the differences of rate of exchange" $=4481$ "Other debts to the budget"

The closing of the expenses and incomes accounts is realized by using the discount accounts and not by account 121 "The patrimonial result".

- the cashing in of the interest which is to be transferred to the state's budget is recorded:

\begin{tabular}{ccc}
\hline 5187 "Interest to be cashed in" & $=4481$ "Other debts to the budget" \\
\hline 5124 "Accounts in currency" & $=5187$ "Interests to be cashed in" \\
\hline
\end{tabular}

Dealing with this subject is a result of the changes which occurred in the legislative frame which governs the activity of capitalization the confiscated or legally entered in the property of the state goods, from the necessity of emphasizing the main aspects of this activity and the observance of the legal frame which controls the book-keeping activity in public institutions.

\section{Bibliography:}

$>$ The law of book-keeping no. 82/1991, re-published in 2005

$>$ The law regarding public finances no. 500/2002

$>$ The Order of the Public Finances Minister no. 1917/2005 with the following modifications and completions

Ordnance no. 14 on $31^{\text {st }}$ of January 2007

$>$ Decision no. 731 on $4^{\text {th }}$ of July 2007 